\title{
New Developments in Coenzyme Q10 Research Contributed by A Single Group. Editorial
}

\author{
Miki Tokunaga ${ }^{1}$, Toru Takahashi ${ }^{2,}$, Ram B. $\operatorname{Singh}^{3}$, M.A. Niaz ${ }^{3}$, Fabien De Meester ${ }^{4}$ and \\ Douglas W. Wilson ${ }^{5}$
}

\author{
${ }^{1}$ Department of Nutrition and Health Sciences, Fukuoka Women's University, Fukuoka, Japan \\ ${ }^{2}$ Department of Nutrition, Graduate School of Human Environment Science, Fukuoka Women's University, Japan \\ ${ }^{3}$ Halberg Hospital and Research Institute, Moradabad, India \\ ${ }^{4}$ The Tsim Tsoum Institute, Krakow, Poland \\ ${ }^{5}$ School of Medicine, Pharmacy and Health, Durham University, UK
}

\begin{abstract}
Coenzyme Q10 (CoQ10), first identified by Moor et al in 1940, is a fat soluble quinone with characteristics common to vitamins [1]. It is found in the organs of various animal species with highest concentrations in the heart, liver, kidney, muscles and pancreas [2, 3]. Festenstein et al in 1955 named the substance ubiquinone [2] while Crane et al in 1957 choose the name coenzyme Q [4]. Ubiquinone is a component of the mitochondrial respiratory chain, participating in electron transport in NADH-coenzyme Q reductase (complex I), succinate coenzyme Q reductase (complex II) and the cytochrome system $[4,5]$. Folkers and his group determined the structure of the quinone moiety which was found identical to that described by Morton and his team, and suggested the name "ubiquinone" referring to the ubiquitous occurrence of this compound in various tissues [2-5]. It is also rich in pancreas and may be protective against type 2 diabetes [6]. In 1957, Crane et al demonstrated that it has an important role as a redox carrier in the mammalian respiratory transport chain [4]. A high concentration of CoQ10 observed in healthy human myocardium has led to the assumption that a myocardial deficiency of CoQ10 is detrimental to cardiac function [7]. In 1972, Littarru, of Italy and the late Prof. Folkers from Texas, documented a deficiency of CoQ10 in human heart disease, particularly among patients subjected to bypass surgery in Houston, USA [8-10].

Lower than normal levels of CoQ10 have also been found in blood samples from patients with cardiovascular diseases (CVDs) compared with levels in healthy human subjects [9, 10]. Yamamura and his group were the first to use CoQ10 for the treatment of cardiovascular disease (CVD) in the 1960's [11] and later Folkers et al. presented the rationale for using CoQ10 in treating congestive heart failure (CHF) [8].
\end{abstract}

Keywords: COENZYME Q10, vitamins, animal species, ubiquinone.

Ubiquinone is naturally present in our diet and synthesized in all body cells especially muscles. The biosynthesis of ubiquinone from the amino acid tyrosine is a multi-stage process requiring at least eight vitamins and several phytochemicals [12]. It is possible that deficiency of any of these micronutrients may result into ubiquinone deficiency. Ramasarma studied the natural occurrence of ubiquinone and its distribution in the body [13]. Stocker and coworkers reported that ubiquionol-10 protects human low density lipoprotein more efficiently against lipid peroxidation than does alphatocopherol [14]. Since then, clinical reports worldwide have described favourable effects of both intravenous and oral CoQ10 in patients with CVDs of various aetiologies [14-16].

*Address correspondence to this author at the Department of Nutrition, Graduate School of Human Environment Science, Fukuoka Women's University, Japan; Tel: +81-92-661-2411; Fax: +81-62-661-2415;

E-mail: takahashi@fwu.ac.jp
There is evidence that CVDs and other chronic diseases may be associated with oxidative stress and deficiency of antioxidant vitamins and minerals resulting in to increased risk of recurrent cardiovascular events and other noncommunicable diseases [17-19].

CoQ10 and antioxidant selenium were administered in patients with acute myocardial infarction in 1994 [20]. Finally, Singh et al conducted a randomized, double blind, placebo controlled trial of CoQ10 in patients with acute myocardial infarction showing significant decrease in cardiac end points for the first time in the literature [21]. Effect of hydrosoluble CoQ10 causing a decline in insulin levels in hypertensive patients with coronary artery disease and reduction in serum concentration of lipoprotein(a) among acute myocardial infarction (AMI) patients were also observed for the first time by Singh et al in 1999 [22, 23]. In view of these beneficial effects of CoQ10 on vascular disease risk [24-27], Singh et al demonstrated for the first time in rabbits that 
CoQ10 can inhibit atherosclerosis and modulate the quality and chemical composition of atheroma [25]. This group also administered CoQ10 in other CVDs in conjunction with taurine $[26,27]$.

Effects of coenzyme Q10 in new indications with antioxidant vitamins deficiency were also reported by Singh et al showing beneficial effects in patients with motor neuron disease and tuberous sclerosis as well as seizures and chronic renal failure [28]. Congestive heart failure may be associated with CoQ10 deficiency as well as with carnitine deficiency $[29,30]$. In a randomized, double blind controlled trial; Singh's group administered both the agents in patients with heart failure for the first time as metabolic treatment of heart failure $[29,30]$. After a follow up period of 12 weeks, there was a significant improvement in ejection fraction and other parameters of heart failure [29]. Serum concentration of IL-6 and TNF-alpha, that are proinflammatory cytokines, showed a significant decline in the intervention group compared to control group which was again a novel discovery for CoQ10. Baseline serum CoQ10 $(0.21 \pm 0.11 \mathrm{v} / \mathrm{s} 0.19+0.10 \mathrm{ug} / \mathrm{ml})$ was low, however, after 12 weeks, serum CoQ10 showed a significant increase in the carni Q-gel group compared to the control group $(2.7 \pm 1.2 \mathrm{v} / \mathrm{s} 0.76 \pm 0.14 \mathrm{ug} / \mathrm{ml})[29,30]$. Serum nitrite which is is an indicator of nitric oxide showed significant increase in the CoQ10 group compared to control group.

Long-term follow up, after treatment for 12 months, the quality of life visual analogous scale revealed that dyspnea, palpitation and fatigue and New York Heart Association (NYHA) class II-III-IV, which were present at rest, in all the patients, at baseline, showed beneficial effects in the intervention group compared to the placebo group [30]. The deaths (3 vs. 8$)$ and hospitalizations due to worsening of heart failure ( 2 vs. 11) among interven-tion and control group respectively, were significantly lower in the carni Qgel group compared to the control group (5 vs. 19, $\mathrm{P}<0.02$ ). Treatment with carni Q-gel was stopped after 12 months. Follow up after another 3 months (total 15 months) revealed that there was a worsening of NYHA class heart failure, as well as in the quality of life symptom scale and physical performance, assessed by 6-min walk test. There was a nonsignificant increase in hospitalizations in the intervention group after cessation of carni Q-gel softsules, compared to hospitalizations during the last 3 months. The findings indicated that treatment with ubiquinol + L-carnitine fumarate can cause a significant improvement in the quality of life, exercise capacity, as well as improvement in The New York Heart Association (NYHA) Functional Classification, which became worst after cessation of CoQ10.

Singh et al also administered CoQ10 in chronic renal failure [31,32]. Ninety-seven patients (mean age, 48 years) with chronic renal failure (serum creatinine $>5 \mathrm{mg} / \mathrm{dl}$ ), with a history of declining renal function for at least 12 weeks, were randomly assigned to receive, in double-blind fashion, (CoQ10; $60 \mathrm{mg}, 3$ times per day orally) (Q-Gel) or placebo for 12 weeks [32]. The 45 patients who were receiving haemodialysis at the start of the study were encouraged to decrease the frequency or stop dialysis if there was an increase in urine output and a decrease in serum creatinine of more than $2 \mathrm{mg} / \mathrm{dl}$. In the patients receiving hemodialysis and CoQ10, the mean serum creatinine concentration de- creased from 9.5 to $6.7 \mathrm{mg} / \mathrm{dl}$; mean blood urea nitrogen (BUN) decreased from 88.2 to $79.8 \mathrm{mg} / \mathrm{dl}$; mean creatinine clearance increased from 40 to $54.9 \mathrm{ml} / \mathrm{min}$; and 24-hour urine output increased from 1,300 to $1,920 \mathrm{ml}$. Renal function tended to worsen in hemodialysis patients receiving placebo, and the differences in the changes between groups were significant $(\mathrm{p}<0.01$ to $\mathrm{p}<0.001)$. Significant improvements in each of these parameters relative to the placebo group were also seen in the non-dialysis patients treated with CoQ10. The number of patients receiving dialysis decreased from 21 to 12 in the CoQ10 group, and remained unchanged at 24 in the placebo group $(\mathrm{p}<0.02)$. Eighty-one percent of the patients receiving CoQ10 had a positive response to treatment.

In a recent study, cerebrospinal fluid (CSF) concentrations of Co Q10 have been reported as a breaking news finding in humans indicating that this biomarker can be used for diagnosis in the diseases of the brain [33]. Effects of Co Q 10 administration in amyotrophic lateral sclerosis (ALS) have been reported again by Kawasaki et al with beneficial effects [34].

In a further study, two patients presented with positive hepatitis B virus antigen reactivity [35]. Both the patients had medical records indicating clinical and biochemical manifestations of viral hepatitis. Treatment with coenzyme Q10 and w-3 fatty acids was associated with reversal of antigenicity causing negative hepatitis $\mathrm{B}$ antigen reactivity, an observation made for the first time in the literature. Endothelial dysfunction in type 2 diabetes and the possible impact on this condition of CoQ10 appears to be interesting [36]. Glucagon like peptide (GLP) produced by the glucagon gene is responsible for insulin secretion. Since CoQ10 is protective against superoxide anion produced due to hyperglycemia, Table $\mathbf{1}$, it poses the possibility that CoQ10 may be protective against free radical induced damage to glucagon gene. Thus proper functioning of GLP may be useful in controlling type II diabetes mellitus [6]. DiPeptidyl Peptidase IV (DPPIV) checks the GLP, thus in order to restore the normal functioning of these, the activity of DPP IV has to be checked using DPP IV inhibitors. CoQ10 might also enhance the activity of DPP IV enzyme which needs further studies related to ligand molecule for target protein in type 2 diabetes [6]. The present studies provide new insights for efficient inhibition of DPP IV to restore the normal activity of the body overcoming the negative effects left by other drugs.

The effect of $\mathrm{CoQ}_{10}$ on endothelial dysfunction in ischaemic heart disease together with recent data highlighting that treatment with $\mathrm{CoQ}_{10}$ increases extracellular SOD activity indicate that this therapy can improve endothelial dysfunction [36]. In a randomized, double blind, placebo controlled trial, the effect of coenzyme Q10 (CoQ10, 120 $\mathrm{mg}$ /day) (2cap BD, $\mathrm{n}=101$ ) and placebo containing inert fibre $(500 \mathrm{mg}$, cap BD, $\mathrm{n}=99$ ) was compared in patients with acute stroke, during a follow up period of 4 weeks [37]. The diagnosis of stroke was proven by computerized axial tomography (CAT) scan in all the patients. In 28 patients, plasma coenzyme Q was determined by HPLC showing low mean levels compared to healthy control subjects (CoQ 0.21 vs. $0.27 \mathrm{ng} / \mathrm{ml}, \mathrm{P}<0.05)$ ). The proportion of brain haemorrhage 
Table 1. Possible Mechanisms of Action of Coenzyme Q10

\begin{tabular}{|c|c|}
\hline 1. & Repletion of CoQ10 deficiency. \\
\hline 2. & Antioxidant activity. \\
\hline 3. & Spares Vitamin E. \\
\hline 4. & Direct free radical scavenger via semiquinone species. \\
\hline 5. & Membrane stabilizing effect due to phospholipid protein interaction. \\
\hline 6. & Preservation of myocardial Na-K-ATPase activity and ATP manufacturing. \\
\hline 7. & Correction of mitochondrial "leak" of electrons during oxidative respiration. \\
\hline 8. & Induction of DT diaphorase which is an inhibitor of free radicals. \\
\hline 9. & Beneficial effect on prostaglandin metabolism. \\
\hline 10. & Inhibition of intracellular phospholipases. \\
\hline 11. & Stabilization of integrity of calcium ion dependent slow channels and possibly potassium channels. \\
\hline 12. & Spares vitamin C, A and beta carotene by decreasing their cell consumption. \\
\hline 13. & Reduced insulin responses in myocardial infarction. \\
\hline 14. & Reduced lipoprotein(a) levels in myocardial infarction. \\
\hline 15. & Reduction in IL-6 and TNF-alpha in heart failure. \\
\hline 16. & Increased serum nitrite indicator of nitric oxide. \\
\hline 17. & Reduced serum creatinine in chronic renal failure. \\
\hline 18. & Reduced albuminuria in renal failure. \\
\hline 19. & Improved endothelial dysfunction \\
\hline 20. & Increase in coenzyme Q10 in cerebro spinal fluid in meningitis and encephalitis. \\
\hline 21. & Inhibition of atherosclerosis. And stabilization of plaque. \\
\hline
\end{tabular}

( 27.7 vs. $25.2 \%, \mathrm{n}=27$ vs. 25$)$ and cerebral infarction (73.2 vs. $74.7 \%, n=74$ vs. 74 ) were comparable respectively. Approximately half of the patients presented with coma grade IV in association with hemiplegia in both the groups and rest half had hemiparesis. The proportion of deaths (13.8 vs. $18.2 \%, 12$ vs. 15 ) was slightly lower in the CoQ group and all accept 2 deaths in infarction,(control group), the deaths were in patients with brain haemorrhage, during the follow up of 4 weeks. These findings have also been confirmed in other studies [36, 38-42]. It is possible that CoQ10 acts as neuroprotective agent in stroke whereas in myocardial infarction, it protects the cardiomyocytes. However, in both the conditions, endothelial dysfunction is important which is improved by CoQ10 administration. Coenzyme Q10 decreases all cause mortality by half, according to the results of a multicentre randomized double blind trial presented at Heart Failure 2013 congress at Lisbon. It is the first drug to improve heart failure mortality in over a decade and should be added to standard treatment, according to lead author Professor Svend Aage Mortensen (Copenhagen, Denmark) of the Q-SYMBIO Trial which included 110 patients from India recruited by Singh,s group in this Trial [42].

Conclusively, Singh's group has demonstrated for the first time that CoQ10 can modulate plasma insulin, lipoprotein(a), serum creatinine and albuminurea, serum IL-
6,TNF-alpha,serum nitritite, blood pressure variability and neuronal degeneration, hence CoQ10 needs exploration for its supplementation in CVDs and other chronic diseases..

\section{CONFLICT OF INTEREST}

Conflict of interest has not been declared by the authors.

\section{ACKNOWLEDGEMENTS}

Acknowledgements are due to International College of Nutrition and International College of Cardiology for logistic support to write this article. We are also thankful to Mr Raj Chopra, Tishcon Corporation, Westbury, NY, for providing highly bioavaiable Coenzyme Q10 for various studies.

\section{REFERENCES}

[1] Lehnininger AI. Oxidation-reduction enzymes and electron transport. In: Biochemistry. $2^{\text {nd }}$ ed. New York: Worth Publishers, 1975; pp. 493-7.

[2] Festenstein GN, Heaton FW, Lowe JS, Morton RA. A constituent of the unsaponificable portion of the animal tissue lipids (lambda $\max 272 \mathrm{m \mu}$ ). Biochem J 1955; 59: 558-66.

[3] Linn BO, Page AC, Wong EI, et al. Isolation and distribution of coenzyme Q10 in animal tissues. Am Chem Soc 1959; 81: 400710. 
[4] Crane FL, Hatefi Y, Lester RL, Widmer C. Isolation of a quinone from beef heart mitochondria. Biochim Biophys Acta 1957; 25: 220-1.

[5] Wolf DE, Hoffman CH, Trenner NR, et al. Coenzyme Q. Structure studies on the coenzyme Q group. J Am Chem Soc 1958; 80: 47528.

[6] Dwivedi SP, Dwivedi N, Singh RB, Srivastava A, Mishra S. In Silico Modeling of Ligand Molecule for Target Protein in Diabetes Mellitus Type II Insight Mechanism. Open Nutraceuticals J 2010; 3: 76-80.

[7] King TE. Ubiquinone proteins and cardiac mitochondria. In: Trumpower BL, Ed. Function of Quinones in Energy Conserving Systems. New York: Academic Press, 1982; pp. 3-25.

[8] Folkers K, Littaru GP, Ho L, Runge TM, Havanonda S, Cooley D. Evidence for a deficiency of coenzyme Q10 in human heart disease. Int J Vitam Res 1970; 40: 380-90.

[9] GP Littarru, Ho L, Folkers K. Deficiency of CoQ10 in human heart disease. Int J Vitam Nutr Res 1972; 42: 291-5.

[10] Littaru GP, Ho L, Folkers AI. Oxidation-reduction enzymes and electron transport. In: Biochemistry. $2^{\text {nd }}$ ed. New York: Worth Publishers 1975; pp. 493-7.

[11] Yamamura Y, Ishiyama T, Yamogami T, et al. Clinical use of coenzyme Q for treatment of cardiovascular disease. Jpn Circ J 1967; 31: 168-9.

[12] Fedacko J, Pella D, Fedackova E, et al. Coenzyme Q10 in Heart and Brain Diseases. Open Nutra J 2011; 4: 69-87.

[13] Ramasarma T. Studies on ubiquinone. J Sci Ind Res 1968; 27: 14764.

[14] Yamamura Y. A survey of therapeutic uses of CoQ10. In: Lenaz G, Ed. Biochemistry, bioenergetics, and clinical applications of ubiquinone. Chickester: John Wiley \& Sons 1985; pp. 479-505.

[15] Stocker R, Bowry WE, Frei B. Ubiquionol - 10 protects human low density lipoprotein more efficiently against lipid peroxidation than does alpha-tocopherol. Proc Natl Acad Sci USA 1991; 88: 164650 .

[16] Takasawa K, Fuse K, Konishi T, Watanabe Y. Prevention of premature ventricular contract- ions with CoQ10 after coronary artery bypass grafting. In: Folkers K, Littarru CP, Yamagami T, Eds. Biomedical and clinical aspects of coenzyme Q. vol. 6. Amsterdam: Elsevier. 1991; pp. 357-9.

[17] Dhalla AK, Hill MF, Singal PK. Role of oxidative stress in transition of hypertrophy to heart failure. J Am Coll Cardiol 1996; 28: 506-14.

[18] Serebruany VL, Ordonez JV, Herzog WR, et al. Dietary CoQ10 supplementation alters platelet size and inhibits human vitronectin (CD 51/CD61) receptro expression. J Cardiovasc Pharmacol 1997; 29: 16-22.

[19] Singh RB, Niaz MA, Ghosh S, et al. Dietary intake and plasma levels of antioxidant vitamins in health and disease; a hospital based case control study. J Nutr Environ Med 1995; 5: 235-42.

[20] Kuklinski B, Weissenbacker E, Fahnrich A. CoQ10 and antioxidants in acute myocardial infarction. Mol Aspects Med 1994; 15(Suppl): 143-7.

[21] Singh RB, Wander GS, Rastogi A, Shukla PK, Mittal A, Sharma JP. Randomized, double blind, placebo controlled trial of CoQ10 in patients with acute myocardial infarction. Cardiovasc Drug Ther 1998; 12: 347-53.

[22] Singh RB, Niaz MA, Rastogi SS, Shukla PK, Thakur AS. Effect of hydrosoluble CoQ10 on blood pressures and insulin resistance in hypertensive patients with coronary artery disease. J Hum Hyper 1999; 13: 203-8.

[23] Singh RB, Chopra RK, Niaz MA, Kapoor R. Serum concentration of lipoprotein(a) decreases on treatment with hydrosoluble CoQ10 in patients with acute coronary artery disease. Discovery of a new role. Int J Cardiol 1999; 68: 23-9.
[24] Singh RB, Rastogi SS, Moshiri M. CoQ10 and its role in heart disease. J Clin Biochem Nutr 1999; 26: 109-18.

[25] Singh RB, Shinde SN, Chopra RK, Niaz MA, Thakur AS, Onouchi Z. Effect of CoQ10 on experimental atherosclerosis and chemical composition and quality of atheroma. Atherosclerosis 2000; 148 275-82.

[26] Singh RB, Neki NS, Kartikey K, et al. Effect of coenzyme Q10 on risk of atherosclerosis in patients with recent myocardial infarction. Mol Cell Biochem 2003; 246: 75-82.

[27] Singh RB, Kartikey K, Charu AS, Niaz MA, Schaffer S. Effect of taurine and coenzyme Q10 in patients with acute myocardial infarction. In: Lombardini Ed. Taurine 5, Beginning the $21^{\text {st }}$ century, The Netherlands: Kluwer Academic 2003; pp. 41-8.

[28] Singh RB, Singh MM. Effects of coenzyme Q10 in new indications with antioxidant vitamins deficiency. J Nutr Environ Med 1999; 9: 223-8.

[29] Kumar A, Singh RB, Saxena M, et al. Effects of carni Q-gel (carnitine plus ubiquinol) on cytokines in patients with heart failure in the Tishcon study. Acta Cardiol 2007; 62: 349-54.

[30] Mechirova V, Kumar A, Singh RB, et al. Randomized, double blind, placebo controlled trial of hydrosoluble ubiquinol and carnitine in patients with heart failure: longterm follow up results in the Tishcon study. Open Nutraceuticals J 2008; 1: 1-6.

[31] Singh RB, Khanna HK, Niaz MA. Randomized, double blind, placebo controlled, trial of coenzyme Q10 in chronic renal failure: Discovery of a new role. J Nutr Environ Med 2000; 10: 281-8.

[32] Singh RB, Kumar A, Niaz MA, et al. Randomized, double blind, placebo controlled trial of coenzyme Q10 in patients with end stage renal failure. J Nutr Environ Med 2003; 13: 13-22.

[33] Singh RB, Naini A. Cerebrospinal Fluid (CSF) Concentration of coenzyme q10 in clinical practice, a breaking news finding in humans. Open Nutraceuticals J 2009; 2: 13-5.

[34] Kawasaki T, Singh RB, Cornelissen G, Halberg F. Effects of coenzyme Q10 administration in amyotrophic lateral sclerosis (ALS). Report of a Case and Review. Open Nutraceuticals J 2012; 5: 18792.

[35] Singh RB, Tokunaga M, Takahashi T, Wilson DW, Gerasimova E, De Meester F. Reversal of immunogenicity of hepatitis $b$ antigen by treatment with nutraceuticals (OMEGA QGEL).Open Nutraceuticals J 2013; 6: (in press).

[36] Littarru GP, Tiano L, Belardinelli R, Watts GF. Coenzyme $\mathrm{Q}_{10}$, endothelial function, and cardiovascular disease. BioFactors 2011; 37: 366-73.

[37] Singh RB, Sharma JP, Niaz MA, Mustafa F, Chandel JP, Littarru GP. Effect of coenzyme q10(qgel) in patients with stroke. Presented in The 5th Conference of the International Coenzyme Q10 Association, Kobe, Nov 9-12, 2007.

[38] Tiano L, Belardinelli R, Carnevali P, Principi F, Seddaiu G, Littarru GP. Effect of coenzyme Q10 administration on endothelial function and extracellular superoxide dismutase in patients with ischaemic heart disease: a double-blind, randomized controlled study. Eur Heart J. 2007; 18: 2249-55.

[39] Alehagen U, Johansson P, Bjornstedt M, Rosén A, Dahlstrom U. Cardiovascular mortality and N-terminal-proBNP reduced after combined selenium and coenzyme Q10 supplementation: A 5-year prospective randomized double-blind placebo-controlled trial among elderly Swedish citizens. Int J Cardiol 2012; 167: 180-6.

[40] Halberg F, Cornelissen G, Singh RB. Timing nutriceuticals. Open Nutraceuticals J 2010; 3: 100-11.

[41] Cornélissen G, Halberg F, Schwartzkopff O, et al. Coenzyme-Q10 effect on blood pressure variability assessed with a chronobiological study design. Abstract, Noninvasive Methods in Cardiology, Brno, Czech Republic, September 14, 2005; p. 10.

[42] Mortensen SA, Kumar A, Dolliner P, et al. The effect of coenzyme Q10 on morbidity and mortality in chronic heart failure. Results from the Q-SYMBIO study. Eur J Heart Fail 2013; 15(51): 820. 